\title{
Hybrid Two Stage Quasi Z Source Boost Converter for Photovoltaic Applications
}

\author{
Jyothi K. ${ }^{1}$, Dr. Usha P ${ }^{2}$. \\ ${ }^{I}$ P.G. Student, Power Electronics, Dayananda Sagar College of Engg., Bangalore, India, \\ ${ }^{2}$ Electrical \& Electronics Engineering Dayananda Sagar College of Engg., Bangalore, India,
}

\begin{abstract}
This paper presents a Hybrid Two Quasi Z-source(HTQZS) DC-DC converter for photovoltaic applications. These are mainly employed to full fill the demand of the voltage boost in photovoltaic applications from the lower value voltage. The traditional $z$ source networks have some limitations in voltage boosting, so the modified $z$ source means the different combination of the LC components is combined to form the hybrid quasi $z$ source networks. This hybrid two quasi $z$ source $d c-d c$ converters can be applied for the $d c-a c, a c-a c$, and ac-dc conversions. The structure of the proposed converter is simpler. This converter adds the benefits to the traditional $z$ source converter. This converter draws the continuous input current. The converter simulated is the combination of two different quasi $z$ source networks. This converter uses the duty cycle less than the traditional $z$ source network and gives the more gain than that. PV panel used as source to converter and then the output is inverted and step up.
\end{abstract}

Key words: PV panel, MPPT, HTZS.

\section{Introduction}

Nowadays the use of power is increased because of the increased population and use of more number of electronic equipments among which some will be high power rated devices. So there is a demand for large amount of power generation in these days and even it will keep increasing in the future generation. So technologies are developed to generate the large amount of power using the available sources of energy in the nature, which is cost efficient and environmental friendly. The renewable energy sources are available in the form of sun, wind, tidal, biomass and others. Using sun as the source of energy photovoltaic systems are developed.

But the output obtained from the photovoltaic panels is of low value, so there is a need of step up of the output voltage from the PV panels. Because the low value voltage cannot be provided to the inverters. Hence the design oh step up dc-dc converters is most. important in PV systems. Till now, many voltage-boost topologies have been explored, namely voltage multiplier, switched-inductor, switched. capacitor, coupled-inductor, voltage. lift, and cascaded, boost techniques. But these methods are all not simple and have less efficiency and more costs.

Many DC-DC converters can either buck or boost the voltages. The converter fed with voltage will buck the voltage and boost when fed with the current. The $\mathrm{Z}$ source converters are those which can do both buck and boost operation and these inverters found applications as active filters to improve the quality of power. The required output obtained from these inverters by varying the shoot through duty ratio. Mitigation of voltage sags can be done using these inverters as they boost the voltage and they provide reliability, flexibility, and reduced harmonics. By controlling the shoot through period makes the $\mathrm{z}$ source converter to produce the voltage higher than the line voltage and because of this they are used in compensation of voltage when there is reduction of voltage level in power systems[2].

The Z Source inverter has become a more interested stream because of its buck-boost. inversion capability. Along with the aforementioned. advantages, the original ZSI also has. some drawbacks, such as discontinuous. input current, high voltage. stresses and limited boost, factor 1/(1-2Ds) (Ds is the shoot-through duty cycle). On top of that, the dc, voltage source and the inverter bridge do not share a same ground. To overcome. such limitations in the original ZSI, various novel impedance-source network, topologies have been presented in numerous works done by various authors. Among the changed Z-source. network topologies, quasiZ-source network is a simple but efficient solution.

The proposed converter in this paper has some additional features compared to the traditional Z-source topology, like continuous input. current, and reduction in capacitor, voltage stress. The hybrid two quasi z source boost dc to dc converter is the combination of the two different QZS networks

The traditional z source inverters have some disadvantages among them discontinuity in the current is significant and also the voltage stress on the capacitors and to overcome such drawbacks different combination $\mathrm{L}$ and $\mathrm{C}$ circuits are formed namely quasi $\mathrm{z}$ source networks. 
Quasi z source network has both current fed topology and voltage fed topology which is similar to the $\mathrm{z}$ source network. Disadvantages with the z source converter are discontinuity of input.current, greater.voltage stress on Switch is more. The $L f$ - $C f$ output filter is used to reduce ripple in the output.current and load voltage respectively [2]. In the reference [21] \& [22] authors have used the MPPT algorithm to obtain the maximum power while harnessing the solar energy.

\section{Configuration Of Hybrid Two Quasi Z Sorce Converter}

The hybrid two quasi Z-source dc-dc converter with the PV panel and inverter is shown in the figure 3. The varied voltage from the PV panel is applied as input to the hybrid 2 quasi z-source converter to obtain the boost output voltage with low duty ratio. The output from the converter is given to the inverter for DC to Ac conversion purpose and then to the load.

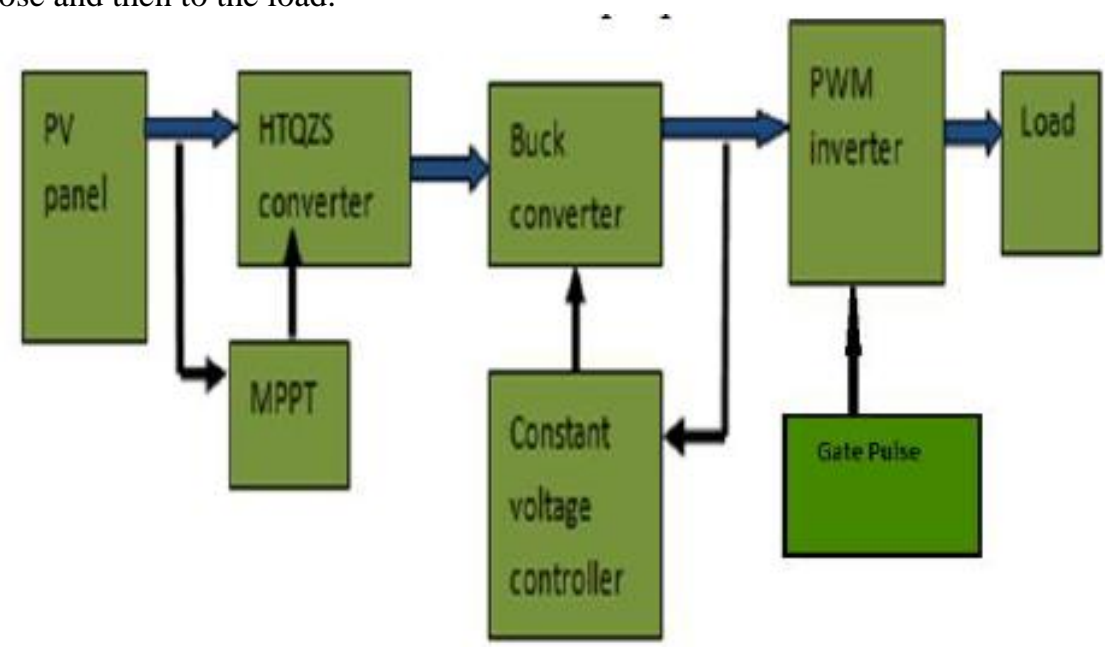

Fig.3. Block diagram of the proposed converter.

\section{Operating Principles Of The Two Quasi Z-Source Converter}

State 0: In this period switch is turned ON. The voltage developed across the capacitors reverse bias the diodes. Capacitors discharge and magnetize the inductors. C2 magnetize the L1. C1, C3, C4 magnetize the L2, L3. During this state energy will be stored in the inductors. There is continuous input current.

According to KVL, the voltages across inductors L1, L2, and L3 can be expressed as

$\mathrm{VL} 1=\mathrm{Vin}+\mathrm{Vc} 2 ; \mathrm{VL} 2=\mathrm{VC} 1+\mathrm{VC} 4 ; \mathrm{VL} 3=\mathrm{VC} 1+\mathrm{VC} 3 ;(1)$

Because of the symmetry in the circuit shown in fig2. (L2 = L3, C3 = C4), we obtain

VL2 = VL3; VC3 = VC4; (2)

State 1: In this mode switch is turned OFF. Capacitors will now be charged by the energy released by inductors which has been stored in this previous mode. Even in this mode there is a input current. The energy released by the inductors is transferred to the load side.

$\mathrm{VL} 1=\mathrm{Vin}-\mathrm{VC} 2 ; \mathrm{VL} 2+\mathrm{VL} 3=-\mathrm{VC} 2 ; \mathrm{VC} 3+\mathrm{VC} 4=\mathrm{VC} 2 ; \mathrm{VO}=\mathrm{VC} 1+\mathrm{VC} 2 ;$ (3)

By applyiing the voltage 2nd balance principle to the inductors L1 and L2 (or L3), from (3.1) - (3.3) we have

$$
\begin{aligned}
& \mathrm{V}_{C 1}=\frac{1-2 D}{1-3 D} \text { Vin; } \quad \mathrm{V}_{C 2}=\frac{2 D}{1-3 D} \text { Vin; } \quad \mathrm{V}_{C 3}=\mathrm{V}_{C 4}=\frac{D}{1-3 D} \text { Vin } \\
& \mathrm{V}_{\mathrm{O}}=\frac{1}{1-3 D} \text { Vin; }
\end{aligned}
$$

Therefore, the $M$ (voltage gain) of the proposed converter is

$$
\begin{aligned}
& \text { given as } \\
& \mathrm{M}=\frac{V_{O}}{V_{\text {in }}}=\frac{1}{1-3 D}
\end{aligned}
$$

In the above equation, we can observe that the step-up ability of the proposed hybrid Z-source network is greater than that of the traditional Z-source networks [3]. 


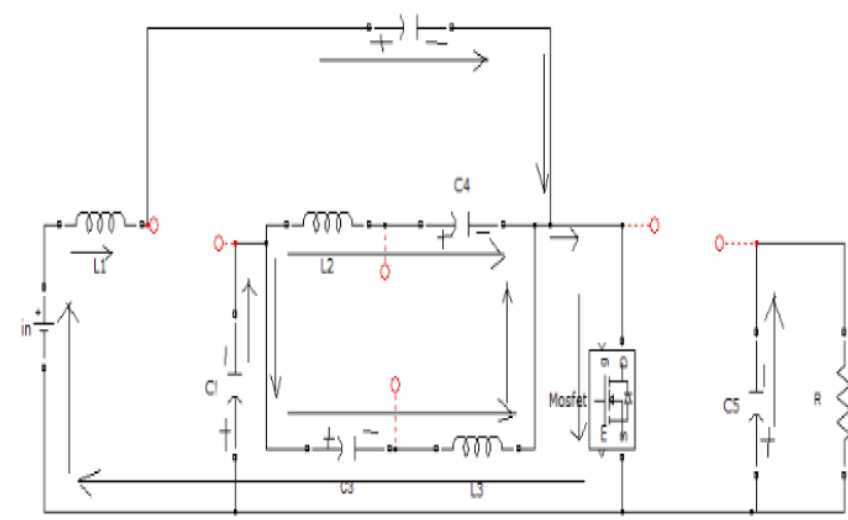

Fig .4 Circuit diagram of state 0 .

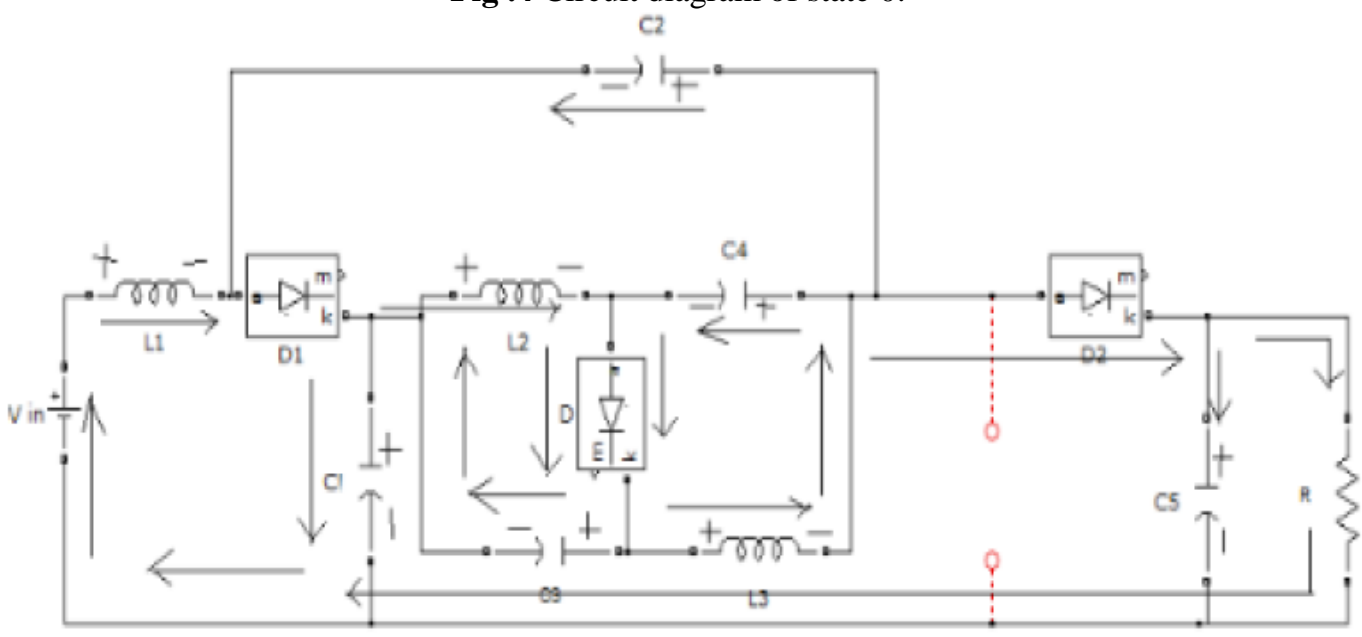

Fig. 5. Circuit diagram of state 1.

\section{Parameter Design}

In general, the design of parameters of a dc to dc converter depends on the components voltage.and current stresses which are mentioned in table I and II. The hybrid two-quasi-Z-source.dc-dc converter parameters design is illustrated.

\section{Parameter Design of Inductor}

The maximum acceptable ripple in current of the inductor is assumed to be $\mathrm{xL} \%$. When the HTQZS.operates in state 0 the equation obtained is

$$
\mathrm{L}=\frac{v_{L d t_{L}}}{d i_{L}}=\frac{v_{L} D T}{x_{L} \% I_{L}}=\frac{v_{L} D}{x_{L} \% I_{L} f}
$$

where $\mathrm{dtL}=\mathrm{DT}$ is the duration of state $0, \mathrm{diL}=\mathrm{xL} \% \mathrm{IL}$ is the ripple in the current of the inductor in the state $0, \mathrm{f}$ $=1 / \mathrm{T}$ is the frequency of switching pulses.

Replacing the expressions of $\mathrm{vL}$ and $\mathrm{L}$ in the above equation the inductances of $\mathrm{L} 1, \mathrm{~L} 2$ and $\mathrm{L} 3$ can be expressed as,

$\mathrm{L}_{1}=\mathrm{L}_{2}=\mathrm{L}_{3}=\frac{D(1-D) V_{\text {in }}}{(1-4 D) x_{\mathrm{L}} \% I_{\text {in }} f}$

\section{PARAMETER DESIGN OF CAPACITOR}

The maximum acceptable ripple in the voltage of the capacitor is considered as $\mathrm{xC} \%$. When the proposed topology operates in state $\mathrm{O}$, the equation mentioned below is derived.

$\mathrm{C}=\frac{i_{C d t_{C}}}{d v_{C}}=\frac{i_{C} D T}{x_{C} \% v_{C}}=\frac{i_{C} D}{x_{C} \%_{C} f}$

where $\mathrm{dtC}=\mathrm{DT}$ is the time interval of state $\mathrm{O}, \mathrm{dvC}=\mathrm{xC} \% \mathrm{VC}$ is the voltage ripple of the capacitor during state $O$.

Substituting the expressions of $\mathrm{iC}$ and $\mathrm{VC}$ in the above equation, the capacitances of $\mathrm{C} 1, \mathrm{C} 2, \mathrm{C} 3$ and $\mathrm{C} 4$ can be derived.

$\mathrm{C} 1=\frac{2 D(1-3 D) I_{\text {in }}}{(1-2 D) x_{C} \% V_{\text {in }} f} \quad \mathrm{C} 2=\frac{(1-3 D) I_{\text {in }}}{2 x_{C} \% V_{\text {in }} f} \quad \mathrm{C} 3=\mathrm{C} 4=\frac{(1-3 D) I_{\text {in }}}{x_{C} \% V_{\text {in }} f}$ 
Parameter Design of Switching Device

The power switch and diodes are choosed with respect to their voltage and current.stresses, as shown in table I and II.

Table I. Voltage Stresses of Switches and Diodes

\begin{tabular}{|c|c|}
\hline \multicolumn{2}{|c|}{ Hybrid Tro Quasi L-Source Boost DC.DCConretter } \\
\hline Parameters & Toltages stress \\
\hline $\mathrm{Cl}$ & $\frac{1-212}{1-30} V$ in \\
\hline Q & $\frac{20}{1-230} V$ \\
\hline C3,CA & $\frac{d}{1-30} V_{\text {in }}$ \\
\hline$D \mid D 2 D, D 3$ & $\frac{1}{1-30} V^{1 / 2}$ \\
\hline S & $\frac{1}{1-30} V_{\text {in }}$ \\
\hline
\end{tabular}

Table II. Current Stresses of Switches and Diodes

\begin{tabular}{|c|c|}
\hline \multicolumn{2}{|c|}{ Hybrid Tro Quasi Z-source Boost DC-DC Converter } \\
\hline Parameters & Current strese \\
\hline $\mathrm{L} 1, \mathrm{~L} 2, \mathrm{L3}$ & Iin \\
\hline D1 & $\frac{l_{\text {in }}}{1-D}$ \\
\hline D2 & $\frac{l_{i n}}{(1-D)^{3}}$ \\
\hline D3 & $\frac{1-30}{1-D}$ Iin \\
\hline S & 3in \\
\hline
\end{tabular}

\section{Perturb and Observe algorithm}

By observing and adjusting the power by varying the voltage is carried out to obtain the maximum power point. Here in the below diagram shows variations in the voltage and power can be observed. In region1 if voltage is varied in positive direction maximum power point can be obtained, if this voltage varied in negative direction then it moves away from the maximum power point. In region2 if the voltage is varied in the positive direction then it is the movement away from the maximum power point and vice-versa.

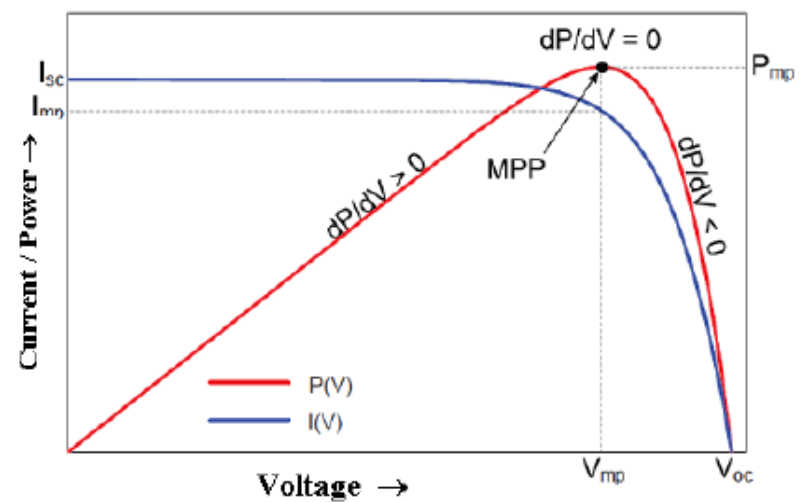

Fig. 6. Graph of the current/power versus voltage of PV panel. 


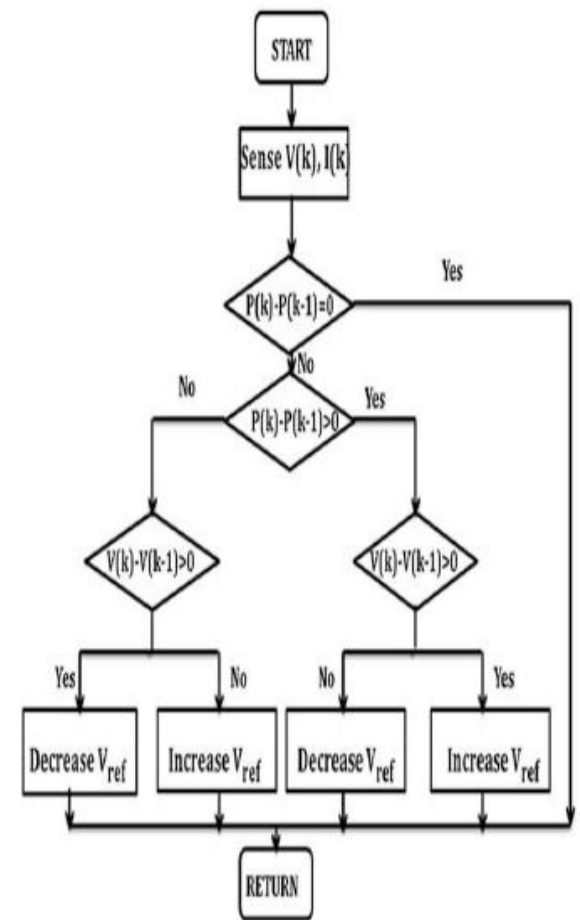

Fig.7. Flow chart of $\mathrm{P} \& \mathrm{O}$ algorithm.

The implementation of $\mathrm{P} \& \mathrm{O}$ algorithm is comparatively easier than other algorithms. So complexity involved in computational process in this method is reduced. Hence applicable to many of the PV devices. The main information it requires is PV voltage. Due to this, the P\&O is one of the most-often used MPPT method in these days. The two main cons of this method are the 58 oscillations around the maximum power point in steady state conditions, and under rapidly-changing irradiation values poor tracking may occur.

\section{Results And Discussion}

Here in this simulation circuit the frequency of switching pulses of the converter's switching device is $30 \mathrm{KHz}$. The results obtained for irradiance value of $1000 \mathrm{w} / \mathrm{m} 2$. Buck converter is used to obtain the output voltage with unchanged value for variable voltage applied at the input side. Pulses for the PWM inverter switching devices is obtained using pulse generator with duty cycle $25 \%$ and frequency is $30 \mathrm{kHz}$. For Vin at $21.58 \mathrm{~V}$ the obtained output DC voltage is around $78.35 \mathrm{~V}$ w.r.t. the duty cycle $(\mathrm{D}=0.25)$. This output is supplied as input to the buck and then to the PWM inverter to generate the AC output and finally stepped up using transformer.

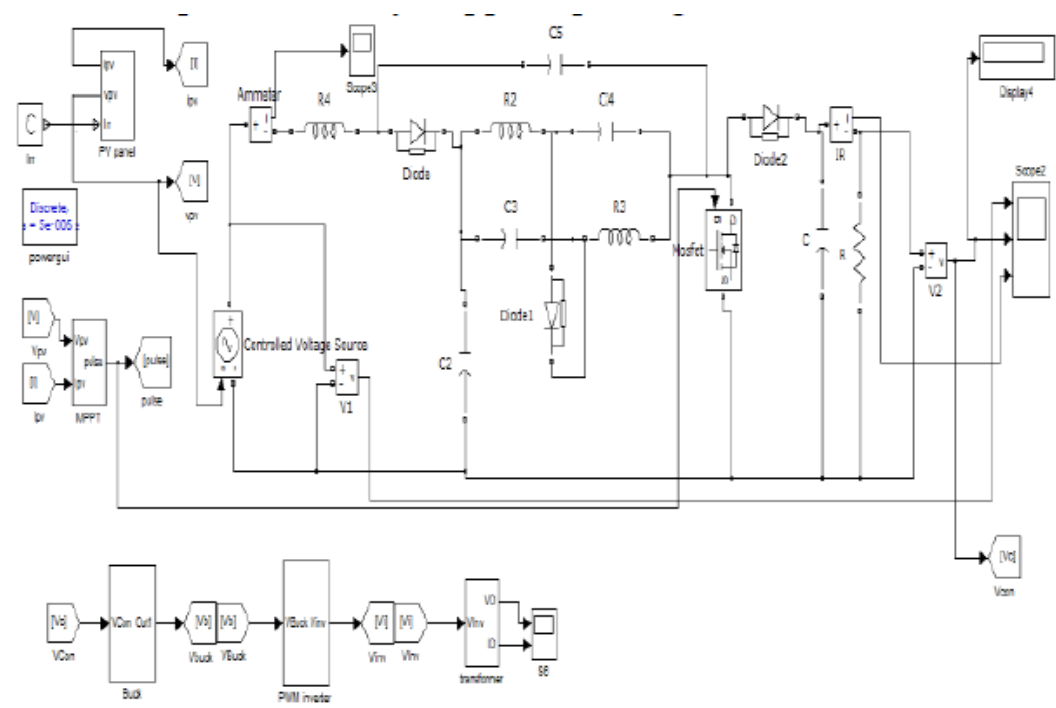

Fig 8. Simulink model of HTQZS converter for photovoltaic applications.. 
TABLE III. OUTPUT VOLTAGES ACROSS PV AND ZSOURCE CONVERTER

\begin{tabular}{|c|c|c|}
\hline $\begin{array}{c}\text { Irradiance Value } \\
\left(\mathrm{W} / \mathrm{m}^{2}\right)\end{array}$ & $\begin{array}{c}\text { PV output } \\
\text { voltage (V) }\end{array}$ & $\begin{array}{c}\text { Proposed converter } \\
\text { o/p voltage (V) }\end{array}$ \\
\hline 500 & 20.59 & 74.24 \\
\hline 600 & 20.85 & 75.30 \\
\hline 800 & 21.26 & 77.00 \\
\hline 1000 & 21.58 & 78.35 \\
\hline
\end{tabular}

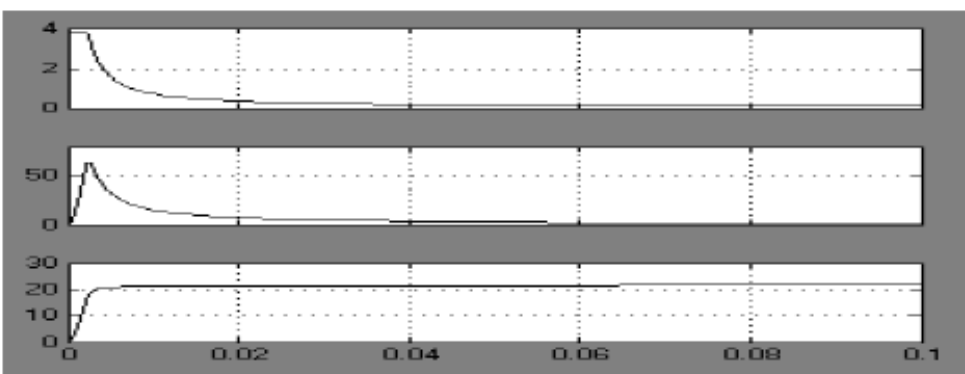

(a)

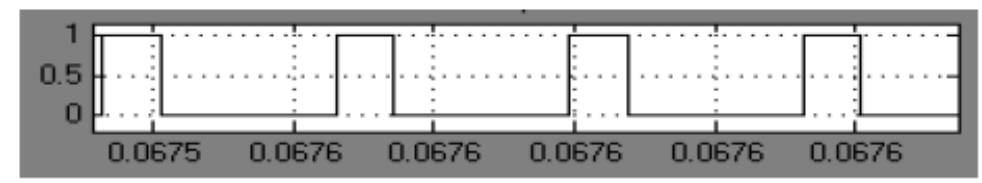

(b)

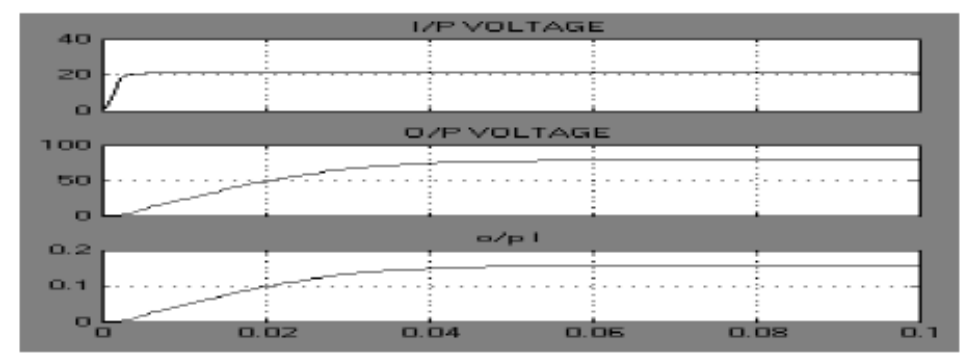

(c)

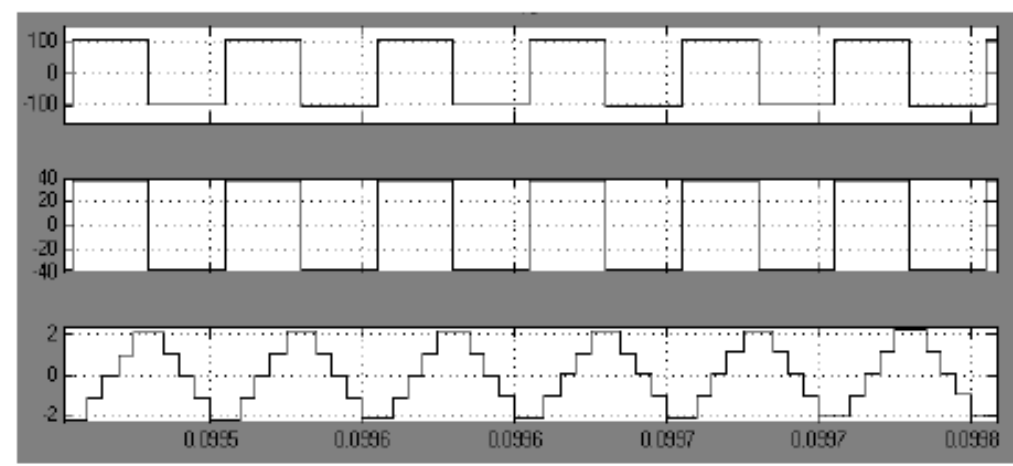

(d)

Fig 7. Simulation waveforms (a). waveform of PV panel output current,power and output voltage; (b). waveform of MPPT pulses; (c). waveform of H2ZS converter's input voltage,output voltage and current; (d) transformer and pwm inverter output voltage and output current respectively. The waveforms of the output voltage of PV and converter are obtained. As per irradiance values different voltage values are obtained. 


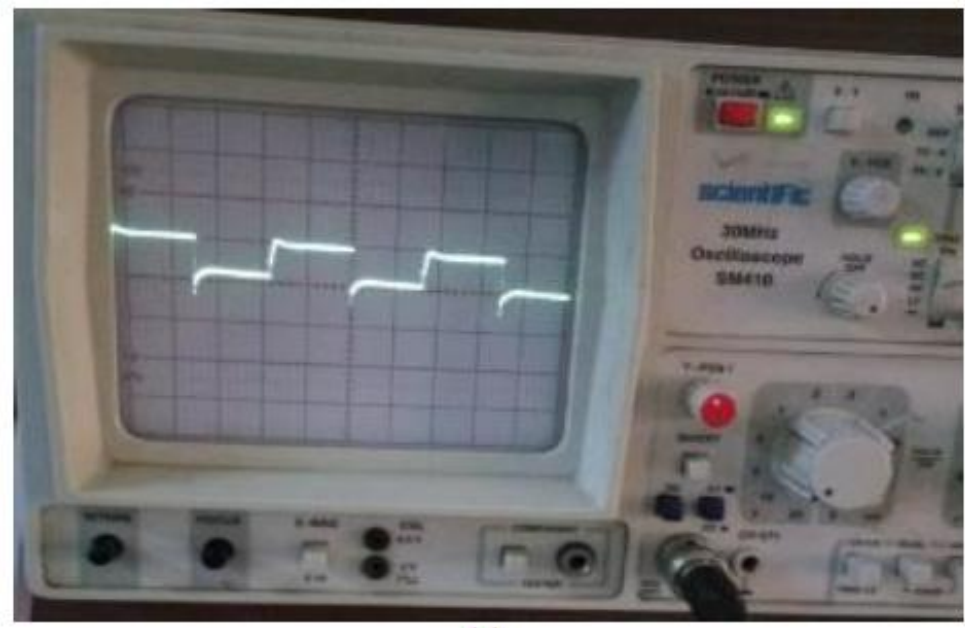

(a)

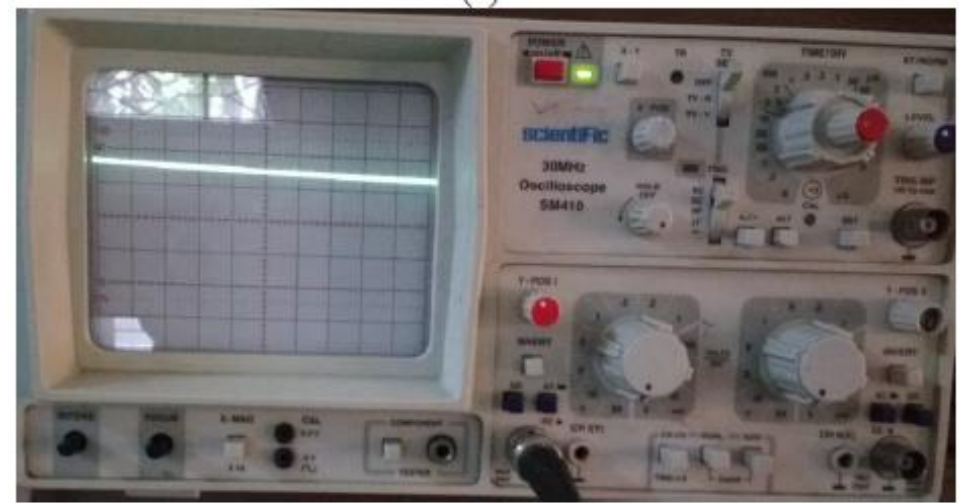

(b)

Fig.8 Experimental results of HTQZS converter.(a).pulse generated from TL494IC.(b).obtained output of 32V for the input of $8 \mathrm{~V}$.

\section{Conclusions}

$\mathrm{Z}$ source networks having boost abilities are used to step up the voltages in photovoltaic systems. But the traditional $\mathrm{z}$ source networks have some limitations to boost the voltages and there is discontinuity of input current and voltage and current stresses. To overcome the above problems modified and combinational $\mathrm{z}$ source networks are built which can be used for the same applications as traditional $\mathrm{z}$ source networks with increased efficiency and gain and even cost effective. In the proposed hybrid network, which is combination of two quasi $\mathrm{z}$ source networks, in this converter the disadvantages of the traditional $\mathrm{z}$ source network has come over and gain is increased. Along with the high step-up abilities, the proposed hybrid Z-source topology possess all the advantages of the previous Z-source networks, such as uninterruptable input current, reduction in capacitor voltage stress and mutual ground between the voltage. source and the inverter bridge. The results of the simulation of the HTQZS converter are obtained. For varied values of Irradiance the simulation is performed and observed the changes. The switching frequency of the device is $30 \mathrm{~K}$. Here in this paper along with the proposed converter PWM inverter is used to obtain AC output.

\section{References}

[1]. J.Anderson and F.Z.Peng, "Four quasi-Z-source inverters," in Proc. IEEE Power Electron. Spec. Conf., Jun. 2008, pp. 2743-2749.

[2]. Suresh, A., Rashmi, M R, Madusuthanan, V. and Kumar, P.V. (2016) "Closed-Loop2Control1of Bi-Directional Soft- Switched Quasi3Z-Source DC-DC Converter" (Scientific Research Publishing). Circuits and Systems, 7, 574-584.

[3]. Baoming Ge, Member, IEEE, Haitham Abu-Rub, Senior Member, IEEE, Fang Zheng Peng, Fellow, IEEE, Qin Lei, Student Member, IEEE, Aníbal T. de Almeida, Senior Member, IEEE, Fernando J. T. E.Ferreira, Senior Member, IEEE, Dongsen Sun, and Yushan Liu, Student Member, IEEE “An Energy Stored Quasi-Z-Source Inverter for Application to Photovoltaic Power System " (IEEE journal).

[4]. Y. Tang, S Xie, C. Zhang, and Z. Xu, "Improved Z-source inverter with reduced Z4Source5capacitor5voltage stress and soft-start capability," IEEE Trans. Power Electron., vol. 24, no. 2, pp. 409-415, Feb. 2009.

[5]. M. K. Nguyen, Y. C. Lim, and G. B. Cho, "Switched-inductor quasi-Z-source inverter," IEEE Trans. Power Electron., vol. 26, no. 11, pp. 3183-3191, Nov. 2011.

[6]. D. Li, P. C. Loh, M. Zhu, F. Gao, and F. Blaabjerg, "Enhanced-boost Z-source5inverters4with alternate-cascaded switched-1and tapped-inductor cells," IEEE Trans. Ind. Electron., vol. 60, no. 9, pp. 3567-3578, Sep. 2013. 
[7]. G. Zhang, B. Zhang, Z. Li, D. Qiu, L. Yang, and W. A. Halang, “A 3-Z-network boost converter,” IEEE Trans. Ind. Electron., vol. 62, no. 1, pp. 278-288, Jan. 2015.

[8]. H. F. Ahmed, H. Cha, S. H. Kim, and H. G. Kim, "Switched-coupled-inductor quasi-Z-source inverter," IEEE Trans. Power Electron., vol. 31, no. 2, pp. 1241-1254, Feb. 2016.

[9]. Anu Raveendran, Elizabeth Paul, Annie P. Ommen, "Quasi Z-Source DC-DC Converter With Switched Capacitor,” International Journal of Engineering Research and General Science Volume 3, Issue 4, July-August, 2015 ISSN 2091-2730

[10]. Amit Kumar Student Member IEEE, Ravindra Kumar Singh Senior Member, IEEE, "Power Loss Calculation of Diode Assisted Cascaded Quasi-Z-Source Converter with CCM and DCM Operation,” IEEE journal 2016 .

[11]. Sruthi S Nair, N. HemaLatha, Dr.Neena Ramesh , "Control of a Large Scale Single Stage Grid Connected PV System Using Fuzzy Controllerwith Capacitor Assisted Extended Boost Quasi ZSource Inverter (CAEB QZSI)," 2015 International Conference on Circuit, Power and Computing Technologies [ICCPCT].

[12]. D. Vinnikov, I. Roasto, T. Jalakas, "Comparative Study of Capacitor-Assisted Extended Boost qZSIs9Operating in Continuous0Conduction Mode," 2010 12th Biennial Baltic Electronics Conference (BEC2010) Tallinn, Estonia, October 4-6, 2010.

[13]. Andrii Chub, Oleksandr Husev, and Dmitri Vinnikov, "Switched-coupled-inductor quasi-Z-source inverter," IEEE journal 2014 .

[14]. Andrii Chub, Dmitri Vinnikov "Single-Switch Galvanically Isolated Quasi-Z-Source DC-DC Converter," 2015 IEEE 5th International Conference on Power Engineering, Energy and Electrical Drives (POWERENG).

[15]. Dmitri Vinnikov, Indrek Roasto, Ryszard Strzelecki, Marek Adamowicz "Performance1 Improvement2Method for the Voltage-Fed qZSI with3Continuous Input Current," IEEE journal 2010.

[16]. Hafiz Furqan Ahmed, Honnyong Cha and Ashraf Ali Khan, Heung-Geun Kim "A Single-Phase Quasi-Z-Source AC-AC Converter with High-Frequency Transformer Isolation,” 2016 IEEE 8th International Power Electronics and Motion Control Conference (IPEMC-ECCE Asia)

[17]. Minh-Khai Nguyen, Young-Gook Jung, and Young-Cheol Lim, "Single-Phase AC-AC Converter Based on Quasi-Z-Source Topology," IEEE TRANSACTIONS ON POWER ELECTRONICS, VOL. 25, NO. 8, AUGUST 2010.

[18]. Chandana Jayampathi Gajanayake, Luo Fang Lin, Gooi Hoay Beng, So Ping Lam, and Siow Lip Kian "Extended boost Z-source inverters," IEEE Research work 2009.

[19]. Dmitri Vinnikov, and Indrek Roasto "Quasi-Z-Source-Based Isolated DC/DC Converters for Distributed Power Generation,” IEEE TRANSACTIONS ON INDUSTRIAL ELECTRONICS, VOL. 58, NO. 1, JANUARY 2011.

[20]. Pradeep S. V., Dr. Usha P., "Implementation of P\&O Algorithm in MPPT controlled Inverse Sepic Converter for Low Power Applications", International Journal of Latest Technology in Engineering, Management \& Applied Science(IJLTEMAS),ISSN 2278-254, Volume 3, Issue 7, July 2014.

[21]. Amit Rashinkar, Dr. Usha P. "Design Of A Super Lift Based Boost Converter using MPPT Technique for Powering Railway Sockets", Imperial Journal Of Interdisciplinary Reasearch(IJIR), Vol-2,Issue-11, October 2016, pp1621-1626, ISSN:2454-1362. 